\title{
Willingness-to-pay for food safety: an experimental investigation of quality certification on bidding behaviour
}

\author{
Anne Rozan* Anne Stenger**, Marc Willinger***
}

Received October 2003, final version received October 2004

\begin{abstract}
We study the impact of new information about food safety on subjects' willingnessto-pay for food products, in an experimental setting. We elicit prices using either a second price auction or the Becker-DeGroot-Marschak procedure. There are three stages of bidding. In stage 1, subjects bid for products without any information. In stage 2, public information about health impact is provided. In stage 3 , new certified products become available, and subjects bid then for non-certified and certified products. The introduction of certified products induces an asymmetric updating of initial bids, bids for non-certified products are lowered, but bids for certified products remain equal to the initial bids.
\end{abstract}

Keywords: Willingness-to-pay, BDM, second price auction, food safety, experimental economics

JEL classification: C9, D18, D83

\section{Introduction}

Over the last decade, the European food industry has experienced various major crises affecting customers, such as the well-known "mad-cow" crisis. As a consequence, many consumers want to be better informed about the characteristics of the food products they buy. Moreover, they often prefer to buy more expensive products, for which quality is certified, rather than non-certified products of unknown quality. In this paper, we try to improve understanding on how new publicly released information about product quality affects a consumer's willingness-to-pay (WTP) for non-certified products and for certified products.

In order to measure precisely how public information affects consumers' willingness-to-pay, we designed an experiment to elicit consumers' buying prices for various food items. The experimental setting, which involves real transactions, is based on the following three-step elicitation procedure. In

\footnotetext{
* University of Strasbourg

** ENGREF-INRA, Nancy

** University of Montpellier
} 
step 1, subjects are asked to state their buying price for a non-certified familiar product (e.g. an apple). In step 2, public information about a food safety indicator is provided (e.g. cadmium content) and subjects are told that the product evaluated in step 1 is of unknown quality. Furthermore, the relationship between the indicator and long-run health is explained to the subjects. In step 3, a certified product, satisfying public health standards, becomes available. Subjects then bid for the product of unknown quality as well as for the certified product. We are interested in how subjects revise their buying price for the non-certified product and how they set their buying price for the certified product.

We elicit buying prices for three different types of products (apples, potatoes and bread), by asking subjects to submit bids in a second price auction or in a Becker-DeGroot-Marschak procedure (BDM). Our sample consisted of adults aged between 20 and 65, who were responsible for food shopping for their household. The food safety indicator was defined in terms of heavy metal concentration in the food items sold, together with a description of long-run health effects of heavy metal intake. The food safety indicators used in the experiment were the results of a chemical analysis, based on advanced measurement techniques, for the heavy metals content of the food products concerned. These indicators were provided for three heavy metals: cadmium, mercury and lead. Participants interacted in a series of experimental markets, in which they could make real transactions for familiar food products. The products are among the most frequently bought by French households.

There is a debate about whether to elicit buying prices in a controlled environment or in the field. Subjects involved in "real" transactions in experimental markets tend to state a lower WTP than the WTP elicited by hypothetical questions, such as those used in field studies (Neill et al., 1994, Blumenschein et al., 1997). The upward bias of the hypothetical WTP has therefore been attributed to the absence of incentives for truthful revelation. With suitable calibration of elicited values, however, hypothetical values could nevertheless be used in the public decision making process. Such calibration, which was first recommended by the NOAA blue ribbon panel (Arrow et al., 1993), could be provided by some incentivecompatible mechanism, such as market mechanisms (Fox et al., 1998; List and Shogren, 1998). This raises a further question as to the relevant mechanism for revealing the respondents' "true" willingness-to-pay. In this paper we address this issue by comparing the bids elicited under the two most frequently employed procedures in experimental studies: the second price (or Vickrey) auction (Vickrey, 1961) and the Becker-deGrootMarschak procedure (Becker et al., 1964), BDM hereafter. They are both incentive-compatible in the sense that they admit a unique dominant strategy that consists in the truthful revelation of private values.

In section 2, the motivation for the experiment is discussed. Section 3 introduces the experimental design. Section 4 reports the results and section 5 concludes. 


\section{Background and motivation}

The main objective of the experiment reported in this paper is to assess the WTP of consumers to avoid health risks. We are particularly interested in health risks generated by long-term accumulation of heavy metals in humans due to repeated consumption of specific food products, especially vegetables, fruits and cereals.

Controlling heavy metal content in food could reduce the health risks due to heavy metal contamination. Today, however, regulatory controls do not exist in most countries. This is the case in France where the present study was performed. The National Council for Public Health provides some general recommendations only, although this situation might change in the near future. At present, the lack of epidemiological data for some heavy metals makes it difficult to assess accurately the risks for human health. In this study, we provide some general public information about long-term health risks of consuming contaminated food. The objective is to assess consumers' WTP for reduced risk of consuming contaminated food products, when information about heavy metal content becomes available. It could be interesting for a public decision maker to know how consumers perceive this risk and how they react to certification.

According to various studies (e.g. Lin and Milon, 1995; Hayes et al., 1995) consumers report higher WTP for food safety when they are exposed to a risk for their own health. More precisely, their WTP is strongly related to the perception of the health risk to which they are exposed. Furthermore, their perception itself is determined to a large extent by their knowledge of the health risk and their confidence in the public health policies implemented by the authorities. In such a context, policies that rely on the labelling of certified products might be a useful guide for consumers. The aim of our study was precisely to analyse how consumers update their WTP for standard products when new certified products are introduced in the market, and simultaneously provide information about the quality of previously available products. When the new products are certified for their quality, there are at least two possible effects on consumers' WTP: they might adjust their WTP for ordinary non-certified products downwards and simultaneously increase their WTP for the certified products with respect to their initial WTP for ordinary products. Earlier findings suggest that the introduction of certified products has a negative impact on the price of ordinary products, but does not necessarily increase the price of the certified products (e.g. Bagnara, 1996, Noussair et al., 2003). Similarly, in a companion paper (Rozan et al., 2003) we found that the introduction of certified products leads to an asymmetric updating process of hypothetical values: the WTP for certified products increases with respect to the initial valuation while the WTP for ordinary products remains unchanged. Furthermore, we observed a similar asymmetric effect of certification for bids elicited with the BDM procedure. However, our earlier analysis of bids did not take into account subjects' boycott behaviour, which was frequently observed 
for non-certified products. It remains therefore an open question how real WTP for certified and non-certified products are adjusted, when boycotts are properly taken into account in the analysis. We address this question by observing consumer subjects' bidding behaviour on experimental markets for ordinary food products. ${ }^{1}$

A secondary objective of our experiment was to compare two alternative and frequently employed elicitation methods, the second price auction (Vickrey, 1961) and the Becker-deGroot-Marschak procedure (Becker et al., 1964). Each of these methods is incentive-compatible in the sense that truthful revelation of a bidder's private value is a dominant strategy.

Several experiments show that the average WTP the two mechanisms elicit tends to differ significantly (Noussair et al., 2003b; Ruström, 1998; Lusk et al., 2003), a result that obviously contradicts the equivalence prediction. Therefore, at least one of the two methods provides a biased estimate of the true WTP. It remains an open question which of the two methods offers the least biased estimate and could serve as a better benchmark for calibrating hypothetical WTP.

Kagel et al. (1987) found that in private value second price auctions, subjects tend to overbid compared to their dominant strategy bid, i.e. bidding the true value. Rütstrom (1998) observed that the second price auction induces higher bids than the English auction. She also found that bids under the BDM procedure are significantly lower than in the second price auction. In a controlled experiment involving a representative sample of the general population, Noussair et al. (2003b) found that the BDM procedure involves larger biases, greater dispersion and slower convergence towards the dominant strategy bid, than the second price auction. Furthermore, under both procedures, their subjects tend to underbid relative to their induced private value. Shogren et al. (2001) suggested that the WTP/WTA discrepancy, pointed out by Kahneman et al. (1990), might be inherent in the BDM procedure. However, the disparity persists under alternative incentive-compatible elicitation mechanisms, including the second price auction. With repetition the disparity vanishes in the second price auction, but not in the BDM procedure. Finally, repetition increases WTP in the second price auction but reduces it for BDM.

A possible reason why the two mechanisms might lead to different estimates of the true WTP is the competitive environment that could develop with the second price auction. The Vickrey auction might induce an upward bias if subjects bid in order to win the auction. However, it can be shown, under fairly general conditions, that individual deviations from the dominant strategy are more costly, in relative terms, in the second price auction than in the BDM procedure (Noussair et al., 2003b). Feedback learning in a repeated trial experiment should therefore allow faster

1 Other studies have addressed WTP for checking for a food pathogen (Hayes et al., 1995), the use of a genetically engineered growth enhancer (Buhr et al., 1993) and the development of irradiation in meat to control Trichinella (Hayes et al., 2002). 
convergence toward the dominant strategy in the second price auction than under the BDM procedure. It is, however, unclear whether deviations from the dominant strategy are also more costly in absolute terms for the second price auction. For a given bid, the expected payoff under the BDM procedure is larger because the probability of winning is larger. In a repeated trial experiment, subjects are therefore likely to submit larger bids under the BDM procedure.

\section{Experimental design}

The use of experimental techniques to assess consumers' WTP has several advantages over other methods such as contingent valuation; it provides better control over WTP elicitation and provides an easily replicable assessment. Furthermore, experiments can help us to understand better the process of price revision when new information becomes available. Experimental techniques have already been successfully applied to value food safety (i.e, Buhr et al., 1993; Hayes et al., 1995; Melton et al. 1996; Shin et al., 1992; Fox et al., 1998; Lusk et al., 2004), and it has been claimed that experimental data can provide estimates comparable to contingent valuation data (Shogren, 1993).

We first describe the subject pool and the products selected for the experiment. Then we discuss the procedures and finally we make some general remarks about the incentives used in the experimental setting.

\subsection{Subjects}

One hundred and twenty adults, aged between 20 and 65, were recruited by an independent private company. To be selected, participants had to be involved in regular food shopping for their household. They were told that they would participate in an experimental session about consumption behaviour for which they would earn a lump sum fee of $150 \mathrm{FF}$ for participating. ${ }^{2}$ The whole sample was split into two smaller samples of 60 persons each, with random assignment. The smaller samples were further divided into groups of 10 subjects, each corresponding to an experimental session.

Six of the groups were trained to use the BDM procedure and the remaining groups were instructed in the use of the second price auction. Table 1 provides summary statistics for variables that were collected at the end of each session. The two samples differ with respect to age and gender. The sample assigned to the second price auction is younger and has fewer female subjects than the sample assigned to BDM. The age interval is 30 to 62 in the BDM treatment and 21 to 59 in the second price auction treatment. The BDM treatment involved 85 per cent female subjects while 
Table 1. Characteristics of the subject sample

\begin{tabular}{lll}
\hline Variable & $\begin{array}{l}\text { BDM } \\
(\mathrm{n}=60) \\
\text { Mean }\end{array}$ & $\begin{array}{l}\text { Second price } \\
(\mathrm{n}=60) \\
\text { Mean }\end{array}$ \\
\hline Age (in years) & 44.9 & 38.7 \\
Gender (female=1) & 0.85 & 0.55 \\
Already informed about heavy metals (yes=1) & 0.52 & 0.52 \\
Perceived health risk (yes=1) & 0.9 & 0.86 \\
Apple consumption at least once per week (yes=1) & 0.75 & 0.67 \\
Potato consumption at least once per week (yes=1) & 0.88 & 0.92 \\
Baguette consumption at least once per week (yes=1) & 0.72 & 0.68 \\
\hline
\end{tabular}

the second price auction involved only 55 per cent females. These differences are significant for gender and age at the $1 \%$ level (t-test).

\subsection{Products}

Participants were asked to post bids for three types of non-certified consumer products: apples, potatoes and bread. Apples were of the Pink Lady variety and potatoes of the Charlotte variety. For bread we chose the baguette that a majority of consumers buy every day in France. All these products are very familiar and widely consumed on a weekly or daily basis. Table 1 indicates that the two samples have the same stated frequencies of consumption for the three products. Samples of these products were tested with respect to mercury, cadmium and lead concentration by the ECPM laboratory. ${ }^{3}$

\subsection{Procedures}

We provide a summary of the procedure implemented in a typical session of the BDM group. The second price auction sessions followed exactly the same format except for the market mechanism used.

Subjects received $150 \mathrm{FF}$ in cash after entering the experiment room. They were given a small envelope containing their code number, and told to keep this number secret throughout the experiment and to report it on each of their answer sheets. Oral instructions were provided by the experimenter with the help of screen overheads. The experiment was divided into 5 stages. The aim of the preliminary stages (1-3) was to familiarise subjects with the procedure to be implemented in the remaining

3 Ecole de Chimie, Polymères et Matériaux (School for Chemistry, Polymers and Materials), University Louis Pasteur, Strasbourg (France). Measurements of cadmium and lead were made with a Varian Spectra AA 400 Graphite Furnace Atomic Absorption Spectrometer with a Zeeman correction. Mercury analysis was performed with a Varian Spectra AA 200 Cold Vapor Atomic Absorption Spectrometer. 
stages (4-5). The main purpose of the preliminary stages was to teach the subjects their dominant bidding strategy. In order to check their understanding of the dominant bidding strategy, we let them participate in an induced private value auction before moving to stages 4-5.

In this paper we concentrate on stages 4 and 5 , which correspond to the subjects' bidding behaviour for the real products. In stage 4, a sample of each of the three products available in the experimental markets was given to each subject: an apple, a potato and a baguette. Subjects could only make a visual and tactile inspection of the products, but were not allowed to taste them. They had enough time to inspect each of the products carefully. After inspection, each subject received a small questionnaire that he was requested to answer for each product separately: (1) How much do you value this product? (2) Do you want to buy this product? (3) If you answered 'yes' to question 2, indicate your buying price.

Note that in contrast to question (3), question (1) is a hypothetical question that was included only because we expected many subjects to refuse to buy our products simply because they had done their food shopping earlier during the day of the experiment. This was very likely, especially with respect to bread, since most French people buy their bread every morning. Asking them to state a hypothetical value was a means of avoiding too many missing observations. The data corresponding to the hypothetical question are reported in Rozan et al. (2003). Here we shall ignore the hypothetical data and focus exclusively on the submitted bids, which are more reliable.

The quantity and price ranges were defined independently for each product (see Table 2). The bidding units were set in integer numbers (Francs) for apples and potatoes and to 50 centimes for bread (see Table 2). To avoid possible income effects for stage 5, subjects were told that they could eventually buy only one item during the experiment. If they won several auctions, one of their winning bids would be selected randomly at the end of the session and implemented.

In stage 5, information about heavy metal content (lead, cadmium an mercury) for each product separately was provided in written form to each subject privately. The same information was also displayed publicly by the use of an overhead projector, so that the information was common knowledge when subjects had to decide how much to bid. The experimenter provided oral comments about the interpretation of the data and additional information about long-term possible consequences of the consumption of

Table 2. Quantity and price range for each product

\begin{tabular}{llll}
\hline & Quantity & Price range (in FF) & Increment (in FF) \\
\hline Apple & $1 \mathrm{~kg}$ & $5-30$ & 1 \\
Potato & $2 \mathrm{~kg}$ & $5-30$ & 1 \\
Baguette & $1 \mathrm{unit}$ & $1-12.50$ & 0.5 \\
\hline
\end{tabular}


food products for which the heavy metal content exceeded the safety standard. After having provided this information, the experimenter distributed a new sample of each product. The only visible difference with the products distributed previously was a tag with the mark: "Checked for Heavy Metal Content". It was explained to the subjects that this label guarantees that the heavy metal content of the corresponding products was below the safety standards presented in the information sheet. Subjects were allowed to check for differences among the products by visual and tactile inspection.

After inspecting the products, new answer sheets were distributed to the subjects, one for each product. On each answer sheet they had to respond to the same questions as in stage 4 , for the certified and the non-certified product. In order to keep the same incentives throughout the evaluation process, the experimenter told the subjects that one of the two stages (4 or 5) would be selected randomly at the end of the experiment and would be used for the real transactions.

Once all the subjects had filled their answer sheets, the real transactions were selected and implemented. The experimenter also asked the subjects to complete a short questionnaire containing personal data (such as age and gender). The session ended with a general discussion allowing subjects to give their impressions and ask questions about the experiment. The average duration of a session was between 1:30 hours and 2 hours.

\subsection{Incentives}

Subjects were aware that winning bidders would have to make real transactions, implying giving up some of their cash holding in exchange for the product for which they were the winning bidder. Why should they submit bids for buying food products sold by the experimenter? There are several reasons. First, the products for sale were standard food items that are regularly consumed on a daily or weekly basis. Second, since these products are usually sold at a posted price, subjects could possibly buy them at lower prices than those for which they are usually sold. The bids submitted by subjects for non-certified products (ex ante) are significantly lower than the market price, for both methods. This indicates that subjects had an incentive to make a "good deal" by participating in the market.

Nevertheless, 35 subjects refused to buy any of the products sold in the experimental markets, 10 in the BDM group and 25 in the second price auction group. We call them non-buyers. A probit analysis revealed no significant difference between the characteristics of the buyers and the nonbuyers. The probability of being non-buyer is only significantly affected by the subject group dummy variable. A possible reason is that subjects assigned to the Vickrey auction treatment had more difficulty in understanding the optimal bidding strategy than subjects assigned to the BDM treatment, and therefore were more likely to refuse to participate in the 
market. In the analysis of the bid updating process, we shall ignore the data for these subjects since nothing can be said about their behaviour. On the other hand, we shall consider as active buyers, subjects who bid for at least one of the products offered in the experimental markets. Furthermore, we shall consider that an active buyer who refuses to buy a given product has a null bid for that particular product. ${ }^{4}$

In the BDM procedure, subjects were asked to submit a buying price privately, knowing that they would only buy the item at the selling price whenever their buying price was higher than the selling price. Subjects who participated in the second price auction were asked to submit a bid secretly, knowing that whenever they had the highest bid they would make a transaction and pay the second highest bid. It is well known that the BDM mechanism and the second price auction are theoretically equivalent, in the sense that they are truth-revealing. They should therefore elicit the same buying prices, since bidding the true value is a dominant strategy in each case. In our experiment, however, we introduced a slight change in the second price auction procedure that might have led to slightly higher bids in the second price auction group than in the BDM group. Our departure from the standard second price auction is a modified "tie-breaking" rule. Let $v_{\mathrm{i}}$ be the private value of subject $i$ for a given good and assume that $v_{n} \leq$ $v_{n-1} \leq \ldots \leq v_{2} \leq v_{1}$ where $n$ corresponds to the number of subjects. If $v_{1}=$ $v_{2}$ and both subjects choose their dominant strategy, they both win the auction. The standard procedure assumes that the second and the first price are equal and therefore that the two players pay their stated bid, therefore earning zero surplus. ${ }^{5}$

\section{Results}

We present the results for the BDM procedure and the second price auction in order, before we compare the two sets of results. To avoid confusion we shall call ordinary products the products available ex ante

4 In our earlier paper (Rozan et al., 2003), we allowed a buyer to be active in one market and inactive in other markets. In the latter case, since he did not bid for the product, his decision was not taken into account for analyzing the bids. Following the recommendation of two referees, we decided for the present analysis to count as active buyers all subjects who decided to buy at least one of the products sold during the experiment. Therefore, the number of active buyers is constant across products in contrast to our previous analysis. Of course, this definition of an active bidder completely changes the analysis.

5 In our experiment, subjects were told that the second price rule would always apply. Therefore, in the case of tied winning bids, subjects could still make a strictly positive surplus, since the two winners would pay the second highest submitted bid. With our modified tie-breaking rule, the dominant strategy is to bid $v_{i}+\epsilon$, where $\epsilon$ stands for the smallest possible bidding increment. It is clear that if the bidding unit is arbitrarily small the dominant strategy is unchanged, but if the increments are discrete numbers as in our case, the dominant strategy is to bid one increment more than the true private value. That is why subjects were trained to bid $v_{i}+\epsilon$, where $\epsilon=0.5$ for baguette and $\epsilon=1$ for the other products. While this tie-breaking rule is unconventional, the elicited values can simply be lowered by one increment in order to obtain the true value, under the assumption that subjects choose their dominant strategy. 
Table 3 : Mean buying prices (in FF) elicited under the BDM procedure and test results

\begin{tabular}{lllllccc}
\hline & $n$ & $P_{0}$ & $P_{\mathrm{NC}}$ & $P_{\mathrm{C}}$ & $P_{\mathrm{NC}}<P_{0}$ & $P_{\mathrm{C}}>P_{\mathrm{NC}}$ & $P_{\mathrm{C}}>P_{0}$ \\
\hline Apple & 50 & $7.69(5.68)$ & $3.38(5.69)$ & $9.55(6.78)$ & $*$ & $*$ & NS \\
Potato & 50 & $6.26(6.77)$ & $3.72(6.45)$ & $8.02(8.19)$ & $*$ & $*$ & NS \\
Baguette & 50 & $2.65(2.27)$ & $1.53(2.33)$ & $3.53(3.57)$ & $*$ & $*$ & NS \\
\hline
\end{tabular}

$n=60-10$ subjects who refused to buy any product.

$P_{0}=$ Average price of ordinary products, (standard deviation in brackets).

$P_{\mathrm{NC}}=$ Average price of non-certified products, (standard deviation in brackets).

$P_{\mathrm{C}}=$ Average price of certified products, (standard deviation in brackets).

$*$ different at the $5 \%$ significance level.

NS $=$ not different at the $5 \%$ significance level.

(before information about heavy metals contents is provided), non-certified products the same products ex post (after information about heavy metals contents is provided) and certified products the new products available after information.

\subsection{Bidding under the BDM treatment}

Table 3 reports the average bid for ordinary, certified and non-certified products. The three remaining columns present the results of a mean comparison test ( $t$-test) for the bid revision process.

Table 3 shows clear patterns for the average bids. When information about heavy metal content is made public, the buying price of non-certified products decreases whereas the buying price of certified products increases, with respect to the ex ante price of ordinary products. Buying prices of certified products are significantly higher than the buying prices of noncertified products. Furthermore, after information is provided, there is a clear tendency for bids for non-certified products to fall, while the prices of certified products are equal to the prices of ordinary products. This asymmetric effect of the process of bid revision is mainly due to the fact that many subjects dropped out of the markets for non-certified products once information was provided (see Table 4). ${ }^{6}$ While at most 4 subjects decided to boycott both the markets for certified and the non-certified products (final line of Table 4), the number of subjects who boycotted only the markets for non-certified products is much larger: 23 for apples, 13 for potatoes and 15 for baguettes.

In our earlier paper (Rozan et al., 2004) we concluded that under the $\mathrm{BDM}$ procedure, the bid revision process was asymmetric with a positive impact on the price of certified products. Under the present analysis, we still find that bid revision is asymmetric, but with a negative impact on the bids for non-certified products. The apparent contradiction between the

6 Note that the columns of table 4 do not sum to 60 , because there are some marginal categories (e.g. 0-0-1) which we decided to omit.) 
Table 4. Entry and exit behaviour in BDM, number of subject

\begin{tabular}{lccc}
\hline$P_{0}-P_{\mathrm{C}}-P_{\mathrm{NC}}$ & Apple & Potato & Baguette \\
\hline $0-1-0$ & 6 & 4 & 4 \\
$1-1-1$ & 13 & 10 & 16 \\
$0-0-0$ & 19 & 30 & 26 \\
$1-1-0$ & 17 & 9 & 11 \\
$1-0-0$ & 4 & 4 & 2 \\
\hline
\end{tabular}

0 if absent in the market, 1 if present in the market.

Ex : 0-1-0 absent for $P_{0}$, present for $P_{\mathrm{C}}$ and absent for $P_{\mathrm{NC}}$.

conclusions of the two studies is due to the fact that the definition of active/ inactive buyers is not the same. In the present paper, a buyer is considered as inactive if during the whole session he never submitted a bid for any of the products. In contrast, an active buyer submits at least one bid during the session. Following the recommendations of two anonymous referees an active buyer who refuses to buy a given product is assumed to have a bid equal to zero for that product. With this assumption subjects who decided to boycott markets for non-certified products have a strong influence on the average bid of non-certified products, which explains the sharp decline in the buying prices of non-certified products.

\subsection{Bidding in the second-price auction treatment}

As shown in Table 5, the results for the second price auction procedure are consistent with the results of the BDM procedure. On average, bids for non-certified products are lower and bids for certified products are higher than bids for ordinary products. However, a few differences are significant. In a manner consistent with the BDM bidding results, there is no significant tendency for certified products to have larger buying prices than ordinary products. However, bids for certified products are higher than for noncertified products, except for potatoes. Furthermore, the decrease in the buying price of non-certified products is significant only for baguette. The

Table 5. Mean bids (in FF) submitted under the second price auction and test results

\begin{tabular}{lllllccc}
\hline & $n$ & $P_{\mathrm{O}}$ & $P_{\mathrm{NC}}$ & $P_{\mathrm{C}}$ & $P_{\mathrm{NC}}<P_{0}$ & $P_{\mathrm{C}}>P_{\mathrm{NC}}$ & $P_{\mathrm{C}}>P_{0}$ \\
\hline Apple & 35 & $4.37(4.78)$ & $3.31(4.70)$ & $5.68(5.11)$ & $\mathrm{NS}$ & $*$ & $\mathrm{NS}$ \\
Potato & 35 & $4.48(5.44)$ & $2.77(4.62)$ & $4.63(5.50)$ & $\mathrm{NS}$ & $\mathrm{NS}$ & $\mathrm{NS}$ \\
Baguette & 35 & $2.35(2.17)$ & $1.31(2.05)$ & $2.67(2.40)$ & $*$ & $*$ & $\mathrm{NS}$ \\
\hline
\end{tabular}

$n=60-25$ subjects who refused to buy any product.

$P_{0}=$ Average price of ordinary products, (standard deviation in brackets).

$P_{\mathrm{NC}}=$ Average price of non-certified products, (standard deviation in brackets).

$P_{\mathrm{C}}=$ Average price of certified products, (standard deviation in brackets).

* different at the $5 \%$ significance level.

NS $=$ not different at the $5 \%$ significance level. 
Table 6. Entry and exit behaviour in the Vickrey auction, number of subjects

\begin{tabular}{lccc}
\hline$P_{0}-P_{\mathrm{C}}-P_{\mathrm{NC}}$ & Apple & Potato & Baguette \\
\hline $0-1-0$ & 3 & 1 & 2 \\
$1-1-1$ & 12 & 10 & 11 \\
$0-0-0$ & 38 & 42 & 38 \\
$1-1-0$ & 6 & 5 & 8 \\
$1-0-0$ & 0 & 1 & 1 \\
\hline
\end{tabular}

0 if absent in the market, 1 if present in the market.

Ex : 0-1-0 absent for $P_{0}$, present for $P_{\mathrm{C}}$ and absent for $P_{\mathrm{NC}}$.

proportion of subjects who boycotted the non-certified products (Table 6) is lower than under the BDM procedure: 9 (instead of 23) for apples, 6 (instead of 13) for potatoes, and 10 (instead of 15) for baguette. The fact that there are fewer boycotts is the main reason why the decrease in buying price is not significant for non-certified products. Note also that at most one subject decided to boycott all markets after information was provided.

\subsection{Comparison of the two treatments}

The two elicitation procedures seem to induce different behaviour, both with respect to bidding and to participation in the market. Both the mean bids and the number of potential buyers appear to be higher with the BDM procedure. To confirm this impression, we provide some more insights about possible explanatory variables for observed differences. In order to compare the 2 procedures, we consider the whole sample, i.e. also the "non buyers". In the second-price auction, the probability of winning the auction is a decreasing function of the number of bidders. Subjects with low values for the good have a lower expected value for winning the auction than under the BDM. Therefore, they are more likely to forego participation in the auction. This is similar to the "throwaway bid" phenomenon (see for example Harstad, 2000; Cox et al., 1992).

According to Table 7, in the second price auction the median price seems to be more stable between the three experimental markets for each product. A meaningful comparison of the two methods requires taking into account the corrected bids for the second price auction, i.e. "bid - 1" for

Table 7. Median bids according to the elicitation procedure (in FF)

\begin{tabular}{lcccccccc}
\hline & \multicolumn{3}{c}{$\mathrm{BDM}$} & & \multicolumn{3}{c}{ Second price auction } \\
\cline { 2 - 4 } & $\mathrm{P}_{0}$ & $\mathrm{P}_{\mathrm{NC}}$ & $\mathrm{P}_{\mathrm{C}}$ & & $\mathrm{P}_{0}$ & $\mathrm{P}_{\mathrm{NC}}$ & $\mathrm{P}_{\mathrm{C}}$ \\
\hline Apple & 11 & 12 & 13 & & 8 & 8 & 8 \\
Potato & 12 & 12.5 & 14 & & 9 & 7 & 9 \\
Baguette & 4.5 & 4 & 5 & & 4.5 & 4.5 & 4.5 \\
\hline
\end{tabular}

(Here we consider only the individuals who bought the product.) 
potatoes and apples, and "bid -0.5 " for bread. Our results suggest that the BDM procedure leads to higher bids on average than the second price auction. Based on a one-factor analysis of variance, we reject the null hypothesis that the average corrected bids are equal (see Table 8). We thereby also reject the assumption that the elicitation procedure has no effect on bids.

The null hypothesis is rejected for 6 cases out of 9. In all other cases the BDM procedure elicits higher bids than the second price auction. In order to assess more precisely the effect of the elicitation method, we ran a regression taking submitted bids as the dependent variable. This regression should allow detection of possible gender and age effects, since as noted in section 3, there were some significant differences in these characteristics between sub-samples. We treated our data as a panel, since a given respondent provided a sequence of bid statements. More precisely, for each respondent we observed 9 bids, which correspond to the 3 ordinary products, the 3 non-certified products and the 3 certified products. Taking bids as the dependent variable $\left(y_{i, t}\right)$ generates a sample of 1080 observations $(60 \times 2 \times 3 \times 3)$. We estimated a random-effects tobit model with left-censored observations, based on the equation $y_{i t}^{*}=x_{i t} \beta+e_{i t}$, where the observed $y_{i t}=0$ if the latent variable $y_{i t}^{*} \leq 0, i=1, \ldots, 120$ identifies the subject and $t$ denotes the circumstances of the bid, with $t=1$ for ordinary, 2 for non-certified and 3 for certified.

Along with the dummy variables for the products (apples, potatoes and bread), for the conditions (ordinary, non-certified and certified), and for the elicitation technique, we included individual characteristics (age, gender, profession etc) as explanatory variables. We applied a stepwise estimation procedure, eliminating variables that were not significant at the 10 per cent significance level. Table 9 reports the results of the final

Table 8. Test of Means comparison based on a one-factor analysis of variance BDM versus second price auction

\begin{tabular}{llllllll}
\hline & & $\mathrm{N}_{1}$ & $\mathrm{BDM}$ & $\mathrm{n}_{2}$ & Second price & $\mathrm{F}_{1,118}$ & Reject $\mathrm{H}_{0}{ }^{*}$ \\
\hline Apple & $P_{0}$ & 60 & $2.21(2.3)$ & 60 & $1.37(2.0)$ & 4.5 & Yes \\
& $P_{\mathrm{NC}}$ & 60 & $1.28(2.2)$ & 60 & $0.77(1.7)$ & 2.0 & No \\
& $P_{\mathrm{C}}$ & 60 & $2.94(3.5)$ & 60 & $1.56(2.3)$ & 6.6 & Yes \\
Potato & $P_{0}$ & 60 & $5.22(6.6)$ & 60 & $2.62(4.7)$ & 6.2 & Yes \\
& $P_{\mathrm{NC}}$ & 60 & $3.1(6.0)$ & 60 & $1.62(3.7)$ & 2.6 & No \\
& $P_{\mathrm{C}}$ & 60 & $6.68(8.1)$ & 60 & $2.7(4.8)$ & 10.9 & Yes \\
Baguette & $P_{0}$ & 60 & $6.41(5.9)$ & 60 & $2.5(4.2)$ & 16.8 & Yes \\
& $P_{\mathrm{NC}}$ & 60 & $2.82(5.3)$ & 60 & $1.93(3.9)$ & 1.1 & No \\
& $P_{\mathrm{C}}$ & 60 & $7.96(7.1)$ & 60 & $3.32(4.8)$ & 17.4 & Yes \\
\hline
\end{tabular}

${ }^{*} H_{0}: P_{\mathrm{BDM}}=P_{\text {second price. }}$ This hypothesis is tested by an F-test, at the $5 \%$ significance level. Standard deviation in brackets.

$P_{0}=$ Average price of ordinary products.

$P_{\mathrm{NC}}=$ Average price of non-certified products.

$P_{\mathrm{C}}=$ Average price of certified products. 
Table 9. Random-effects Tobit regression

\begin{tabular}{lclcc}
\hline Bid & Coeff. & Std. Err & $t$ & $P>|\mathrm{t}|$ \\
\hline BDM & $5.70^{*}$ & 1.2 & 4.7 & 0.00 \\
Apple = reference & & & & \\
Potato & $-1.66^{*}$ & 0.7 & -2.2 & 0.03 \\
Baguette & $-4.54^{*}$ & 0.7 & -6.0 & 0.00 \\
Ordinary = reference & & & & \\
Non-certified & $-5.26^{*}$ & 0.8 & -6.6 & 0.00 \\
Certified & $1.40^{*}$ & 0.7 & 1.9 & 0.05 \\
Age & $4.26^{*}$ & 1.6 & 2.6 & 0.01 \\
Intercept & $-7.84^{*}$ & 1.9 & -4.0 & 0.00 \\
\hline
\end{tabular}

Number of obs. $=1080 \quad$ Log likelihood $=-1655.19$.

Wald Chi2(6) $=133.07 \quad$ Prob $>$ Chi $2=0.000$.

* different from zero at the $5 \%$ significance level.

regression, showing that the dummy variable for the type of bidding procedure affects the bids significantly for all three products even when controlling for the age difference. The dummy variable representing gender was not significant. This allows us to conclude that the observed differences in the data are at least partly due to differences in the bidding behaviour induced by the two methods. Our results contrast, however, with the findings of Lusk et al. (2003) who showed that by repeating the second price auction, bids tend to become higher in the second price auction than under the BDM procedure. Their result could be explained by the feedback learning provided by the repetition of the second auction. In our case, the fact that subjects are repeatedly involved in an auction does not lead to a tendency to bid higher over time in the auction than under the BDM procedure.

\section{Conclusion}

This paper reports the results of an experiment involving real transactions for familiar food products. In the experiment, buying prices for food products were elicited on the basis of observed bids in a second price auction or under the BDM procedure. Two types of food products were available: non-certified products and certified products. It was explained that the two product types differed only with respect to heavy metal concentration. In the case of a non-certified product the heavy metal concentration was unknown, while for certified products it was precisely measured and compatible with public health standards. The experiment had two main objectives. The first one was to investigate our hypothesis that new public information that is damaging for non-certified products would induce two adjustments: first, a decrease in the buying price for noncertified products, and second, an increase in the buying price for certified products (with respect to the initial buying price of ordinary products, i.e. 
non-certified). We observed, as predicted, that buying prices for noncertified food products decrease when such information is made public. However, the buying prices for certified products did not significantly increase with respect to the non-certified products, although the average price increased. Our results confirm earlier findings by Noussair et al. (2003a), who observed that releasing information about the GMO content of food products severely decreased consumers' WTP. Furthermore, in accordance with Noussair et al. (2003a) we also observe that many subjects exit the market for the non-certified products after the adverse information has been released, thereby adopting a boycott position. We interpret the decrease in WTP and the boycott position as indications that consumers are really concerned about food safety issues. A policy implication is that public authorities should release more information on the quality of food products in order to meet consumers' expectations.

Our second objective was to compare two standard methods for eliciting WTP, the BDM procedure and the second price auction. While both methods involve the same incentives for truthful revelation of private values, we observed the BDM procedure led to significantly higher bids than the second price auction. These findings agree with earlier results in the literature showing that the two methods produce conflicting estimates of buying price. At the same time, our results contrast with earlier findings that overbidding might be higher under the second price auction (e.g. Kagel et al., 1987, Rüstrom, 1998). There is as yet no consensus about which of the two methods is more likely to elicit the true willingness-to-pay. Further investigation is therefore required.

\section{Acknowledgements}

The research reported in this article was financially supported by INSERM and the French Ministry of Environment. We thank Alexandra Demangeon, Roseline Bouchon and Kene BounMy for their assistance in running the experiments. We also thank Marc-Jacques Ledoux, Faramarz Rastegar and Anne Boos for their assistance. We are grateful to François Laisney and Charles Noussair for very helpful comments and suggestions on an earlier version of this paper.

\section{References}

Arrow, K., Solow, R., Leamer, E., Portney, P., Radner, R. and Schuman H. (1993). Report of the NOAA Panel on Contingent Valuation. Federal Register 58(10): 46014614.

Bagnara, G. L. (1996). Consumer willingness to pay for food safety: results from a survey on peaches. Proceedings of the XIIIth International Symposium on Horticultural Economics, August 4-9. The State University of Nex Jersey. Acta Horticulturae 429: 157-164.

Becker, G., DeGroot, M. and Marschak, J. (1964). Measuring utility by a single response sequential method. Behavioral Science. 9: 226-232.

Blumenschein, K., Johannesson, M., Blomquist, G., Liljas, B. and O'Conor, R. M. (1997). Hypothetical versus real payments in Vickrey auctions. Economics Letters. 56: 177180. 
Buhr, B. L., Hayes, D. J., Shogren, J. F and Kliebenstein, J. B. (1993). Valuing ambiguity: the case of genetically engineered growth enhancers. Journal of Agricultural and Resource Economics 18: 175-184.

Cox, J. A, Shogren, J. F, Hayes, D. J and Kliebenstein, J. B. (1998). Calibrating Contingent Values with experimental auctions markets. American Journal of Agricultural Economics 80: 455-465.

Fox, J. C, Smith, V. L., Walker, J. M. (1992). Theory and Misbehaviour of First-Price Auctions: Comment. American Economic Review 82: 1392-1412.

Harstad, R. (2000). Dominant strategy adoption and bidders'experience with pricing rules. Experimental Economics 3: 261-280.

Hayes, D. J, Fox, J. A., and Shogren J. F. (2002). Experts and activists: how information affects the demand for food irradiation. Food Policy 77: 40-53.

Hayes, D. J, Shogren, J. F, Shin, A. Y and Kliebenstein, J. B. (1995). Valuing food safety in experimental auction markets. American Journal of Agricultural Economics 77: 4053.

Kahneman, D., Knetsch, J. and Thaler, R. (1990). Experimental tests of the endowment effect and the Coase theorem. Journal of Political Economy 98: 1325-1348.

Kagel, J., Harstad, R., Levin, D. (1987). Information impact and allocation rules in auctions with affiliated private values : a laboratory study. Econometrica. 55: 12751304.

Lin, C. T. J., Milon, J. W. (1995). Contingent Valuation of health risk reductions for shellfish. In Caswell, J. A. (ed.) Valuing Food Safety and Nutrition. Westview Press. Boulder-San Francisco- Oxford, 83-114.

List, J. and Shogren, J. F. (1998). Calibration between actual and hypothetical bids in a field experiment. Journal of Economic Behavior and Organization 37: 193-205.

Lusk, J. L., Feldman, T. and Schroeder, T. C. (2003). Experimental auction procedure: impact on valuation of quality differentiated goods. Americam Journal of Agricultural Economics, 86 (2): 389-405.

Lusk, J. L., House, L., Valli A., Jaeger, S. R., Moore, M., Morrow, B., and Traill, W. B. (2004). Effect of information about benefits of biotechnology on consumer acceptance of genetically modified food: evidence from experimental auctions in the United States, England and France. European Review of Agricultural Economics. 31(2): 1-26.

Melton, B. E, Huffman, W. E. and Shogren, J. F. (1996), Economic values of pork attributes : hedonic price analysis of experimental auction data. Review of Agricultural Economics 18: 613-627.

Neill, H., Cummings, R., Ganderton, P., Harrison, G. and McGukin, T. (1994). Hypothetical surveys and real economic commitments. Land Economics 70: 145-154.

Noussair, C., Robin, S. and Ruffieux, B. (2003a). Do consumers really refuse to buy genetically modified food? Economic Journal, in press.

Noussair, C., Robin, S. and Ruffieux, B. (2003b). Revealing Consumers' willingness-topay : a comparison of the BDM mechanism and the Vickrey auction, Journal of Economic Psychology, in press.

Rozan A., Stenger A., Willinger M., 2003, "The effect of heavy metal content on food pricing behaviour: experimental assessment", in Risk and Uncertainty in Environmental and Natural Resource Economics, J. Wesseler, H. P. Weikard, R. Weaver ed., Edward Elgard, chapter 15, 459-473. 
Rutström, E. (1998). Home-grown values and incentives compatible auction design. International Journal of Game Theory 27: 427-441.

Shin, S. Y., Kliebenstein, J., Hayes, D. J. and J. F. Shogren. (1992). Consumer willingness to pay for safer food products. Journal of Food Safety 13: 51-59.

Shogren, J. F. (1993). Experimental markets and environmental policy. Agricultural and Resource Economics Review 12: 117-129.

Shogren, J. F., Cho, S., Cannon Koo, C., List, J., Park, P., Polo, P. and Wilhelmi, R. (2001). Auction mechanisms and the measurement of WTP and WTA. Resource and Energy Economics 23: 97-109.

Vickrey, W. (1961). Counterspeculation, auctions and competitive sealed tenders. Journal of Finance 16: 8-37.

Corresponding author: Anne Rozan, BETA, PEGE, Université Louis Pasteur, 61 avenue de la Forêt-Noire, 67 000, Strasbourg. E-mail: rozan@cournot.u-strasbg.fr. 